\title{
Why Methanol Electro-oxidation on Platinum in Water Takes Place Only in the Presence of Adsorbed $\mathrm{OH}$
}

\author{
Dalila S. Mekazni, Rosa M. Arán-Ais, Adolfo Ferre-Vilaplana,* and Enrique Herrero*
}

Cite This: ACS Catal. 2022, 12, 1965-1970

Read Online

ABSTRACT: Untangling the mechanism of the methanol electrooxidation on platinum in water as a model reaction is essential to optimize fuel cells using alcohols as fuel. Recent experiments unexpectedly suggested that this electro-oxidation process would take place only in the presence of adsorbed $\mathrm{OH}$. The here reported results, carefully obtained under low methanol concentrations on the three basal planes of platinum at different scan rates to discriminate between oxidation and adsorption processes, confirm such an unexpected preliminary observation. It is found that adsorbed $\mathrm{CO}$ from methanol is only formed when adsorbed $\mathrm{OH}$ is already present

\section{barrier-less methanol activation}

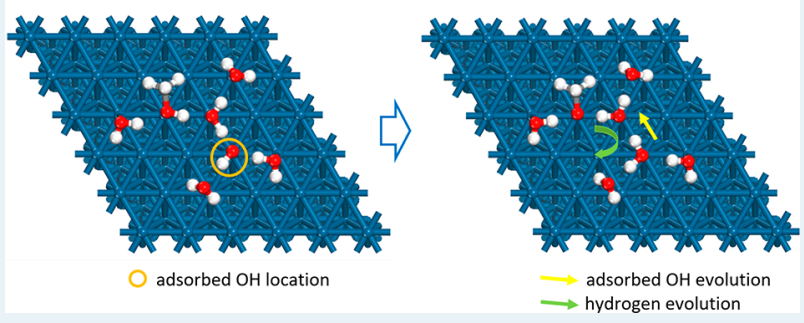
on the surface. This observation is a clear indication that adsorbed $\mathrm{OH}$ is involved in the mechanism beyond providing the oxygen group required to oxidize adsorbed $\mathrm{CO}$, which has never been considered before. Supported by density functional theory calculations, the role played by adsorbed $\mathrm{OH}$ in the methanol electro-oxidation to $\mathrm{CO}$ on platinum in water and the reason why this reaction is not observed in the absence of adsorbed $\mathrm{OH}$ are also here both elucidated. A combination of kinetic and thermodynamic factors, such as the presence of multiple water molecules per methanol molecule, the high adsorbed $\mathrm{OH}$ mobility on the surface, the favorable coadsorption of methanol in the presence of adsorbed $\mathrm{OH}$, and the favorable and virtually barrier-less hydrogen transference from the hydroxy group of methanol to adsorbed $\mathrm{OH}$ to yield water result in the immediate activation of methanol (as soon as the molecule approaches the surface) through the favorable substitution of adsorbed OH by adsorbed methoxy. This contribution represents a change of paradigm in the understanding of how alcohols are electro-oxidized in reference systems and have crucial implications in the search for better electrocatalysts.

KEYWORDS: electrocatalysis, methanol oxidation, platinum, reaction mechanism, $\mathrm{OH}$ adsorption

$\mathrm{B}$ eing liquids at room temperature, alcohols are more easily stored than hydrogen to be oxidized in fuel cells. ${ }^{1-4}$ As a counterpart, higher oxidation overpotentials are required to oxidize alcohols. ${ }^{5-8}$ Thus, untangling the mechanism of the methanol electro-oxidation on platinum in water (the simplest alcohol on the reference anode in the most environmentally friendly solvent) as a model reaction is essential to optimize these $^{\text {processes. }}{ }^{9-18}$ The complete oxidation of methanol to $\mathrm{CO}_{2}$ involves six electron transfers and multiple steps, ${ }^{5-8}$ according to

$$
\mathrm{CH}_{3} \mathrm{OH}+\mathrm{H}_{2} \mathrm{O} \rightarrow \mathrm{CO}_{2}+6 \mathrm{H}^{+}+6 \mathrm{e}^{-}
$$

The main path of the reaction probably proceeds through the adsorbed CO intermediate, ${ }^{19}$ according to

$$
\mathrm{CH}_{3} \mathrm{OH}+\mathrm{Pt} \rightarrow \mathrm{Pt}-\mathrm{CO}+4 \mathrm{H}^{+}+4 \mathrm{e}^{-}
$$

which is subsequently oxidized to $\mathrm{CO}_{2}$

$$
\mathrm{Pt}-\mathrm{CO}+\mathrm{H}_{2} \mathrm{O} \rightarrow \mathrm{Pt}+\mathrm{CO}_{2}+2 \mathrm{H}^{+}+2 \mathrm{e}^{-}
$$

Isotopic labeling unequivocally shows that $\mathrm{O}-\mathrm{H}$ bond cleavage is the first step in the methanol decomposition on platinum under high vacuum conditions. ${ }^{20}$ Also, it is accepted that methanol $\mathrm{C}-\mathrm{H}$ bond cleavage is the rate-determining step in the methanol electro-oxidation on platinum in water. ${ }^{20,21}$ Moreover, it is generally recognized that solvent effects would have a role in the mechanism, though it is not completely understood yet.

Through exploration of interfacial aspects of this electrooxidation process, it has been recently and unexpectedly found that the methanol electro-oxidation onset on the $\operatorname{Pt}(111)$ surface in water coincides with that of $\mathrm{OH}$ adsorption. $^{22}$ Preliminary observations suggest that adsorbed $\mathrm{OH}$ would be involved in the reaction mechanism beyond providing the oxygen group required to oxidize adsorbed $\mathrm{CO}$. The participation of adsorbed $\mathrm{OH}$ in this mechanism has never been considered before. ${ }^{23-25}$ In other oxidation mechanisms, such as those related to $\mathrm{CO}$ oxidation on gold and copper, the

Received: November 8, 2021

Revised: December 10, 2021

Published: January 21, 2022

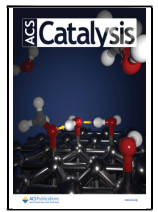


participation of adsorbed $\mathrm{OH}$ explains the unexpected activities found for the reaction. ${ }^{27,28}$ Also, it has been shown that preadsorbed oxygen favors the methanol activation in ultrahigh vacuum (UHV). ${ }^{26}$ To further explore this issue, new voltammetric experiments performed under low methanol concentrations on single crystal platinum electrodes at different scan rates to discriminate between faradic oxidation and adsorption processes are here discussed. Since methanol oxidation currents on platinum are much lower than diffusion limiting currents, methanol oxidation currents are almost independent of the scan rate on this metal. By contrast, the adsorption currents originated by adsorbed $\mathrm{H}$ and $\mathrm{OH}$ are proportional to the scan rate. Thus, at low scan rates, the oxidation currents dominate these voltammetric profiles, being the adsorption currents masked by the faradaic current. By contrast, at high scan rates, the adsorption processes dominate the profiles, enabling the comparison of these processes to those registered in the absence of methanol. The here reported results confirm that methanol electro-oxidation on platinum in water takes place only in the presence of adsorbed $\mathrm{OH}$. Supported by density functional theory (DFT) calculations, a complete explanation is provided for that.

In the voltammetric profiles displayed in Figure 1, it can be observed that, at low scan rates, the methanol oxidation onset

Evs. RHE/V

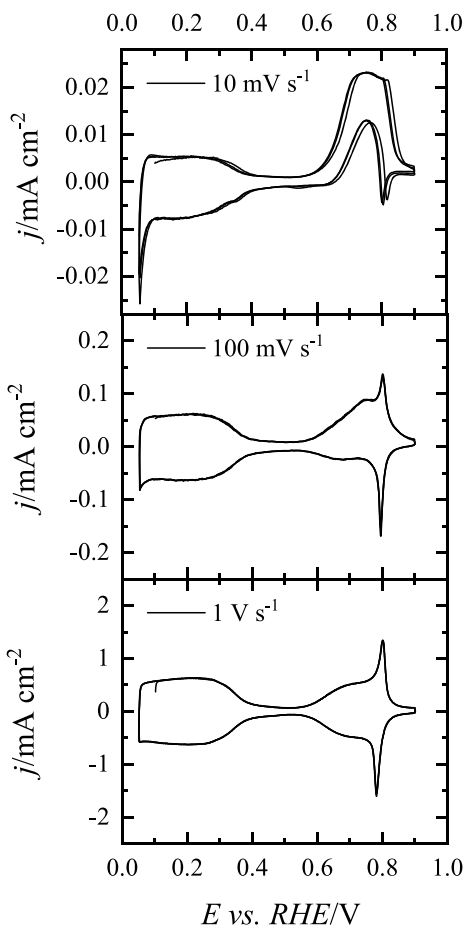

Figure 1. Voltammetric profiles (three full cycles) for the $\mathrm{Pt}(111)$ electrode in $0.1 \mathrm{M} \mathrm{HClO}_{4}+0.1 \mathrm{mM} \mathrm{MeOH}$ at selected scan rates.

on $\operatorname{Pt}(111)$ is $0.6 \mathrm{~V}$. This onset potential coincides with that for $\mathrm{OH}$ adsorption on this electrode. At $10 \mathrm{mV} \mathrm{s}^{-1}$, the current reaches a plateau centered at ca. $0.72 \mathrm{~V}$, sharply diminishing for $E>0.8 \mathrm{~V}$. This potential is very close to that for the sharp peak observed in the absence of methanol, which marks the $\mathrm{OH}$ adlayer completion in the absence of methanol. In the negative scan direction, oxidation currents increase from $0.8 \mathrm{~V}$, being negligible for $E<0.6 \mathrm{~V}$. The profile is stable upon cycling and no $\mathrm{CO}$ accumulation on the surface is detected since the hydrogen adsorption profile coincides with that obtained in the absence of methanol. As the scan rate increases, the voltammetric profile evolves to that obtained in the absence of methanol (given that oxidation currents are independent of the scan rate and adsorption currents linearly increase with it). This evolution can be more easily appreciated when these profiles are represented in capacitance units by dividing the current density by the scan rate (Supporting Information Figure S1). In fact, the profile obtained at $1 \mathrm{~V} \mathrm{~s}^{-1}$ coincides with that at $50 \mathrm{mV} \mathrm{s}^{-1}$ in the absence of methanol, the only difference being the slight displacement of the sharp peaks at $0.8 \mathrm{~V}$ (Figure S2). As the scan rate increases, these peaks slightly shift as a result of kinetic effects on the $\mathrm{OH}$ adsorption process. It is worth noting that the oxidation profile for methanol at high scan rates on this electrode qualitatively differs from that for formic acid, where a signal related to adsorbed formate can be clearly observed. ${ }^{29}$ This difference provides evidence that methanol adsorption on this electrode is weak and does not interfere with those of $\mathrm{H}$ and $\mathrm{OH}$.

When the voltammetric profiles for the $\mathrm{Pt}(111)$ electrode obtained in the absence and presence of methanol are compared (Figure S3), it is clear that $\mathrm{OH}$ is already adsorbed on the surface when $\mathrm{CO}_{2}$ is produced from methanol. In fact, it can be concluded that methanol oxidation on this electrode takes place only in the presence of adsorbed $\mathrm{OH}$. Oxidation currents appear exclusively in the $\mathrm{OH}$ adsorption region, the oxidation being inhibited at $0.9 \mathrm{~V}$ after the $\mathrm{OH}$ adlayer completion. Upon completion of the $\mathrm{OH}$ adlayer, there are not enough contiguous free sites for methanol to adsorb, so that the reaction is inhibited. From the observed behavior, it can be proposed that adsorbed $\mathrm{OH}$ takes part in the oxidation mechanism. In the absence of methanol, the $\mathrm{OH}$ adlayer completion is signaled by the peaks at $0.8 \mathrm{~V}$. In the presence of methanol and at low scan rates, these peaks overlap with the methanol oxidation current, being displaced to more positive potentials both in the positive and negative scan directions. This behavior clearly indicates that methanol and adsorbed $\mathrm{OH}$ are interacting and that adsorbed $\mathrm{OH}$ is probably being consumed in the oxidation reaction. The participation of $\mathrm{OH}$ in the oxidation mechanism gives rise to lower adsorbed $\mathrm{OH}$ coverages at low scan rates (when reaction conditions are close to the $\mathrm{OH}$ adsorption equilibrium). At high scan rates, when the $\mathrm{OH}$ adsorption rate is much higher than that of oxidation, the adsorbed $\mathrm{OH}$ consumption originated by methanol oxidation is negligible.

Unlike the $\mathrm{Pt}(111)$ electrode, the $\mathrm{H}$ and $\mathrm{OH}$ adsorption processes on the $\mathrm{Pt}(100)$ electrode overlap. $\mathrm{OH}$ adsorption starts at ca. $0.38 \mathrm{~V},{ }^{30,31}$ coinciding with the final stage of $\mathrm{H}$ desorption, so that, at $0.42 \mathrm{~V}, \mathrm{H}$ and $\mathrm{OH}$ coverages are the same. ${ }^{32}$ In the presence of methanol, additional currents between 0.4 and $0.9 \mathrm{~V}$ can be observed in the profiles for this electrode (Figure 2). At low scan rates, the profile for the first cycle differs from that for the second and subsequent ones. This observation indicates that $\mathrm{CO}$ is being formed and adsorbed on the surface during the oxidation cycles. As before, as the scan rate increases, the profiles evolve toward that obtained in the absence of methanol (Figures S4 and S5), being almost identical at high scan rates. To determine the origin of the observed currents, the profiles obtained in the absence and presence of methanol at low scan rates are compared in Figure S6. The main peak at ca. $0.64 \mathrm{~V}$ can be assigned to adsorbed $\mathrm{CO}$ oxidation according to reaction $3 .^{33}$ The signal appearing at $0.45 \mathrm{~V}$ in the first scan, which is not 


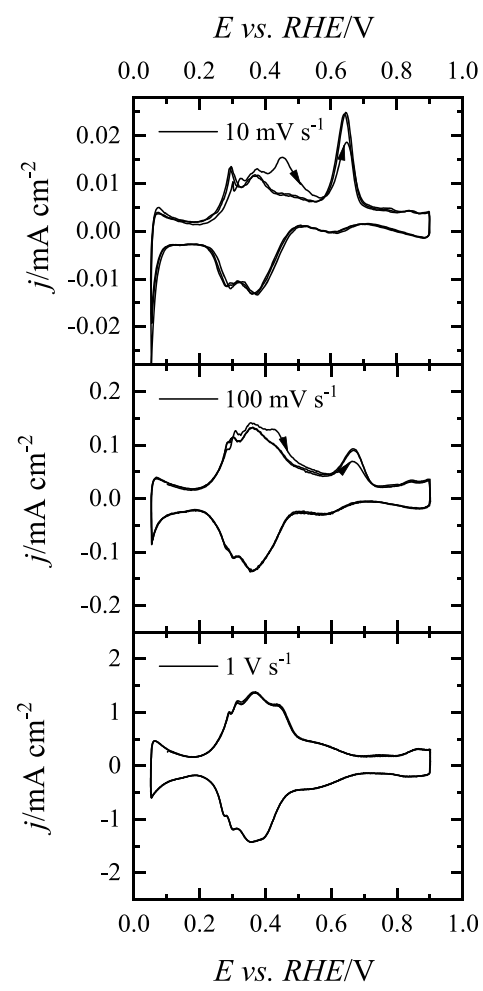

Figure 2. Voltammetric profiles (three full cycles) for the $\operatorname{Pt}(100)$ electrode in $0.1 \mathrm{M} \mathrm{HClO}_{4}+0.1 \mathrm{mM} \mathrm{MeOH}$ at selected scan rates. The arrows mark the first positive scan direction of the profile.

present in the profile recorded in the absence of methanol, can be tentatively assigned to $\mathrm{CO}$ formation according to reaction 2. Thus, the onset for this signal matches that of $\mathrm{OH}$ adsorption on this electrode, providing evidence that $\mathrm{OH}$ adsorption and $\mathrm{CO}$ formation are linked processes on this surface. In fact, the chronoamperometric curves for methanol oxidation on this electrode indicate that $\mathrm{CO}$ formation takes place from $0.4 \mathrm{~V}^{34,35}$ This fact explains the differences between the first and subsequent cycles. When the electrode is immersed at $0.1 \mathrm{~V}$, hydrogen readily forms a full adlayer. In the positive scan direction, hydrogen is progressively desorbed, as also happens in the absence of methanol. At the $\mathrm{OH}$ adsorption onset, methanol forms adsorbed $\mathrm{CO}$ according to reaction 2 , giving rise to the signal peaking at $0.45 \mathrm{~V}$. The $\mathrm{CO}$ oxidation onset for this electrode is ca. $0.6 \mathrm{~V} .{ }^{36}$ From this potential, $\mathrm{CO}$ oxidation occurs in the peak centered at $0.64 \mathrm{~V}$. At higher potentials, additional methanol molecules are oxidized. In the negative scan direction, at potentials between 0.6 and $0.4 \mathrm{~V}$, adsorbed $\mathrm{CO}$ is again accumulated, blocking partially the surface. Thus, in the second scan, at $0.1 \mathrm{~V}$ the surface is already partially blocked by adsorbed $\mathrm{CO}$, and the full hydrogen adlayer cannot be formed. In the second scan, when $\mathrm{H}$ is desorbed and $\mathrm{OH}$ adsorption starts, $\mathrm{CO}$ formation according to reaction 2 is hindered by the presence of previously adsorbed $\mathrm{CO}$, explaining the smaller currents obtained in this region during the second and subsequent scans. Despite that, the CO oxidation peak is higher because adsorbed $\mathrm{CO}$ has been accumulated during both the negative and positive scan directions. After the second cycle, stationary conditions are attained, and no additional changes are observed upon cycling.

To corroborate that the peaks at $0.45 \mathrm{~V}$ in Figures 2 and S6 are linked to $\mathrm{CO}$ formation on $\mathrm{Pt}(100)$, a charge analysis can be performed. The ratio between the $\mathrm{CO}$ formation charge according to reaction 2 and the $\mathrm{CO}$ stripping according to reaction 3 should be 2 . However, this charge ratio cannot be easily estimated since additional processes are involved in these peaks. The $\mathrm{CO}$ oxidation peak at $0.64 \mathrm{~V}$, whose charge stands for $69 \mu \mathrm{C} \mathrm{cm}^{-2}$, includes the charge exchanged in the $\mathrm{OH}$ readsorption process on the sites previously occupied by adsorbed $\mathrm{CO}$. The peak at $0.45 \mathrm{~V}$ contains the charge for the $\mathrm{CO}$ formation process and the charge involved in the $\mathrm{OH}$ adsorption on the free sites non-occupied by CO. To eliminate the adsorbed $\mathrm{OH}$ contribution, the profile obtained in the absence of methanol can be used as baseline, resulting in 86 $\mu \mathrm{C} \mathrm{cm}^{-2}$. However, this baseline overestimates $\mathrm{OH}$ adsorption because, in the presence of adsorbed $\mathrm{CO}$, lower $\mathrm{OH}$ coverages will be attained. Under these conditions, the estimated charge ratio $(86 / 69=1.25)$ is lower than expected. However, the CO oxidation charge and the $\mathrm{CO}$ formation charge have been overestimated and underestimated, respectively, almost in the same amount. The correction due to the $\mathrm{OH}$ coverages can be estimated from the maximum $\mathrm{OH}$ coverages, which is estimated to be close to $0.5 .^{30}$ Thus, every two adsorbed $\mathrm{CO}$ molecules displace an adsorbed $\mathrm{OH}$ species, and when two $\mathrm{CO}$ molecules are oxidized, an $\mathrm{OH}$ species is re-adsorbed. Therefore, from the measured $\mathrm{CO}$ oxidation charge $(69 \mu \mathrm{C}$ $\mathrm{cm}^{-2}$ ), $55 \mu \mathrm{C} \mathrm{cm}^{-2}$ would correspond to $\mathrm{CO}$ oxidation and 14 $\mu \mathrm{C} \mathrm{cm}{ }^{-2}$ to $\mathrm{OH}$ adsorption. With this correction, the ratio would be $(86+14) /(69-14)=1.8$, which is close to the expected value (within the errors of the measurements).

In the voltammetric profiles for methanol oxidation on $\mathrm{Pt}(110)$ displayed in Figures 3 and S7, oxidation currents are observed above $0.5 \mathrm{~V}$ in the positive scan direction. $\mathrm{CO}$ displacement experiments indicate that $\mathrm{OH}$ adsorption takes place below $0.2 \mathrm{~V}$ on this electrode. ${ }^{37}$ Thus, adsorbed $\mathrm{OH}$ is

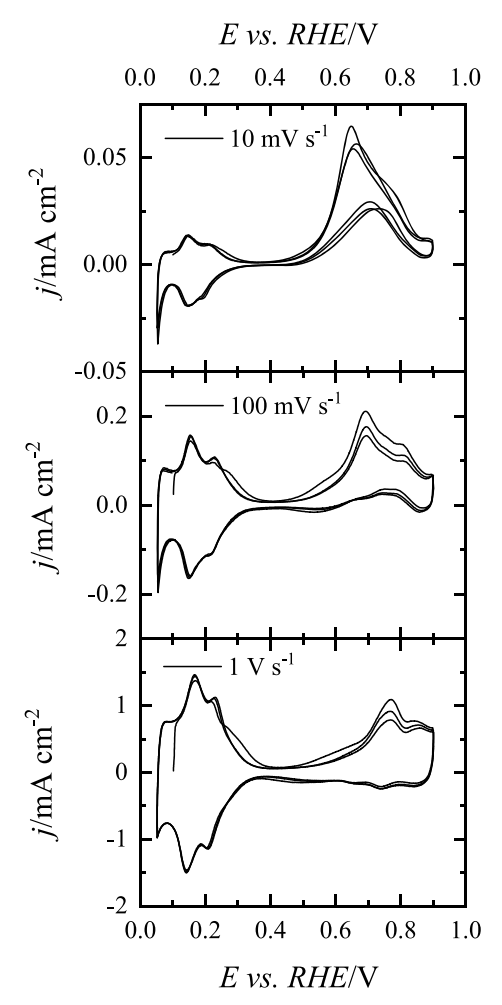

Figure 3. Voltammetric profiles (three full cycles) for the $\operatorname{Pt}(110)$ electrode in $0.1 \mathrm{M} \mathrm{HClO}_{4}+0.1 \mathrm{mM} \mathrm{MeOH}$ at selected scan rates. 


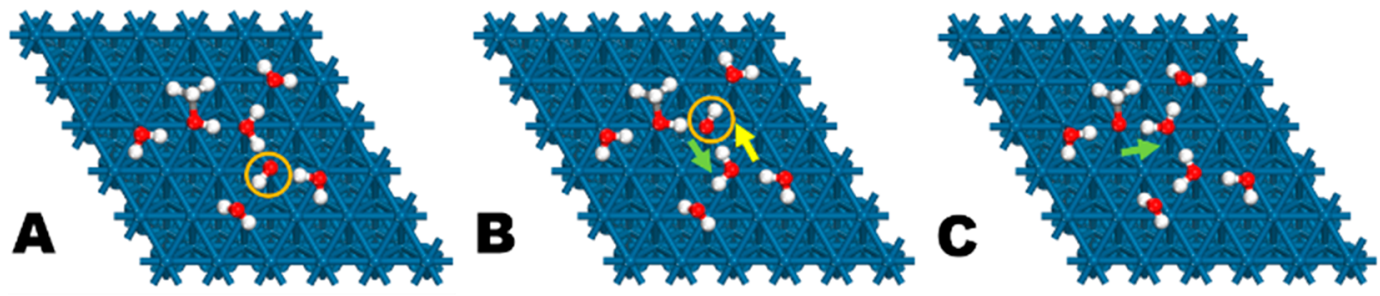

Figure 4. Adsorption configurations on the $\mathrm{Pt}(111)$ surface in water involving methanol, adsorbed $\mathrm{OH}$, and their recombination to yield water. (A) Adsorbed methanol in the presence of nonadjacent adsorbed $\mathrm{OH}$. (B) Coadsorbed $\mathrm{OH}$ and methanol on adjacent locations. (C) Adsorbed methoxy formed with the aid of adsorbed $\mathrm{OH}$ to yield water. Orange circles highlight adsorbed $\mathrm{OH}$ locations and yellow and green arrows emphasize adsorbed $\mathrm{OH}$ and hydrogen evolutions with respect to the previous state, respectively.

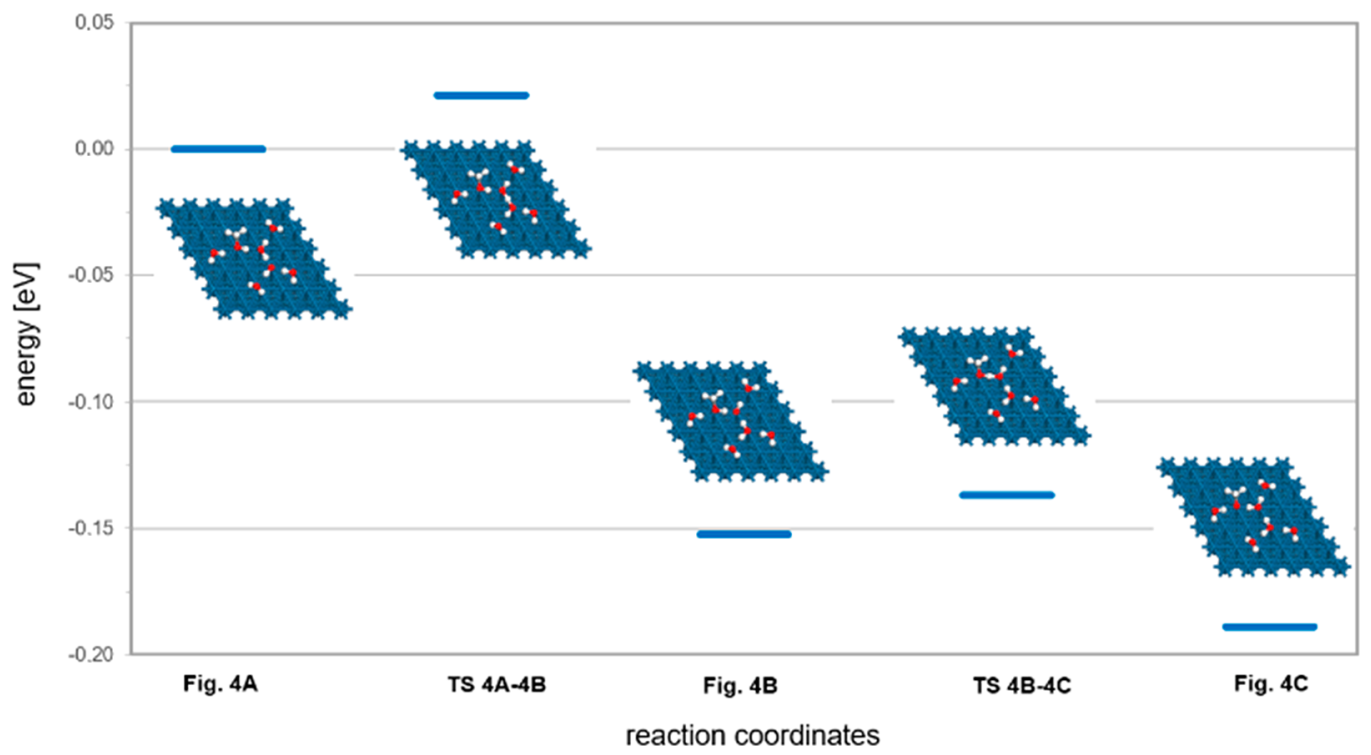

Figure 5. Energy profiles for the virtually barrier-less methanol activation on the $\mathrm{Pt}(111)$ surface in the presence of adsorbed $\mathrm{OH}$ (using the adsorption configurations from Figure $4 \mathrm{~A}-\mathrm{C}$ and the corresponding transition states).

already present on the surface at the immersion potential and $\mathrm{CO}$ can be formed, although a specific $\mathrm{CO}$ oxidation peak is not observed. Currents are significantly smaller in the negative scan direction, since surface oxidation, which is an irreversible process for $E>0.8 \mathrm{~V}$, hinders methanol oxidation. A small evolution can be appreciated in the profiles upon cycling. This is probably due to surface oxidation/reduction processes, which induce the presence of surface defects. Unlike the other two electrodes, oxidation is here still noticeable at $1 \mathrm{~V} \mathrm{~s}^{-1}$ (Figures S7 and S8). At this scan rate and low potentials, the voltammograms show some differences from that obtained in the absence of methanol, which can be also observed at lower scan rates (Figure S9). These differences are likely due to the presence of adsorbed $\mathrm{CO}$, which blocks the surface and reduces the charge for hydrogen adsorption. The differences between the first and successive scans are minimal, indicating that $\mathrm{CO}$ is already formed at the immersion potential.

To elucidate the role played by adsorbed $\mathrm{OH}$ in the methanol electro-oxidation to $\mathrm{CO}$ on platinum in water, DFT calculations on periodic models of the $\mathrm{Pt}(111)$ surface were carried out. Different configurations involving methanol, adsorbed $\mathrm{OH}$, and their recombination (to yield water) were considered (Figure 4). In these configurations, the $\mathrm{OH}$ coverage (0.05) corresponds to that observed just after the onset potentials. In Figure 5, the energies for adsorbed methanol in the presence of nonadjacent adsorbed $\mathrm{OH}$ (Figure $4 \mathrm{~A}$ ), coadsorbed $\mathrm{OH}$ and methanol on adjacent locations
(Figure 4B), and adsorbed methoxy formed with the aid of adsorbed $\mathrm{OH}$ to yield water (Figure 4C) are compared. Transition states were also considered.

When the total energy for adsorbed methanol in the presence of nonadjacent adsorbed $\mathrm{OH}$ (Figure 4A) is compared to that for coadsorbed $\mathrm{OH}$ and methanol in adjacent locations (Figure 4B), it can be concluded that methanol adsorption on the $\operatorname{Pt}(111)$ surface in water is significantly favored in the presence of adsorbed $\mathrm{OH}$ (Figure 5). The negligible barrier between these states additionally ensures that adsorbed $\mathrm{OH}$ on a nonadjacent location will evolve quickly toward the most favorable coadsorption location. Thus, this effect contributes to a better methanol fixation on the surface. Moreover, when the total energy for coadsorbed $\mathrm{OH}$ and methanol (Figure 4B) is compared to that for dehydrogenated methanol (Figure 4C), it is observed that hydrogen from the hydroxy group of methanol can be favorably transferred to adsorbed $\mathrm{OH}$ to yield water during the methanol electro-oxidation on the $\mathrm{Pt}(111)$ surface in water in the presence of adsorbed $\mathrm{OH}$ (Figure 5). The negligible barrier between these states additionally assures the high probability of this step. Then, both combined mechanisms give rise to the immediate activation of methanol on the $\mathrm{Pt}(111)$ surface in water in the presence of adsorbed $\mathrm{OH}$ as soon as the molecule approaches the surface. With the methanol $\mathrm{C}-\mathrm{H}$ bond being much less polarized, adsorbed $\mathrm{OH}$ and methanol coadsorption is not favored through this bond. Thus, the 
presence of adsorbed $\mathrm{OH}$ has a crucial effect on the methanol electro-oxidation on platinum in water, as it has been experimentally evidenced. These mechanisms explain how the methanol $\mathrm{OH}$ bond cleavage is favored under solvation conditions in water. However, these effects do not explain the reason why methanol electro-oxidation on platinum in water is not observed in the absence of adsorbed $\mathrm{OH}$

To further understand the methanol electro-oxidation mechanism on platinum in water, the direct methanol dehydrogenation on platinum in the absence of adsorbed $\mathrm{OH}$ was also investigated using DFT. In agreement with previous DFT calculations, ${ }^{17,18}$ it has been found that the methanol $\mathrm{C}-\mathrm{H}$ bond can be more easily cleaved on the $\mathrm{Pt}(111)$ surface than the methanol $\mathrm{O}-\mathrm{H}$ bond, both under high vacuum conditions and in water, which seems to disagree with the experiments (Table S1). However, before these bond cleavages can occur, the $\mathrm{C}-\mathrm{H}$ (and the $\mathrm{O}-\mathrm{H}$ ) bond have to be unfavorably elongated by a non-insignificant amount, so that each atom can simultaneously interact with each one of a pair of adjacent platinum atoms of the surface, respectively. This requirement determines that these direct dehydrogenation processes on platinum, both in the vacuum and under solvation conditions, are only accessible after surmounting significant barriers (between ca. 0.70 and $1 \mathrm{eV}$ ) during the short time interval in which the methanol molecule is in close contact with the surface (methanol weakly interacts with platinum). In any case, large overpotentials are required for that (greater than $0.7 \mathrm{~V}$, as the barriers would suggest). But, well before reaching such potential values, the surface is already covered by adsorbed $\mathrm{OH}$, formed by the direct adsorption of $\mathrm{OH}^{-}$from solution, which is rapidly regenerated by the multiple water molecules that are in a much more continuous close contact with the surface. This mechanism explains how the methanol $\mathrm{OH}$ bond cleavage is favored under solvation conditions in water, and why significant methanol electro-oxidation on platinum in water is not observed in the absence of adsorbed $\mathrm{OH}$. The experimental evidence that methoxy formation is the first step in vacuum can be explained by the preferred adsorption geometry of the methanol molecule with the surface, which favors the interaction through the hydroxy group. ${ }^{20}$ Under electrochemical conditions, the presence of adsorbed $\mathrm{OH}$ favors the methanol $\mathrm{O}-\mathrm{H}$ bond scission, so that it is no longer the rate-determining step, as observed in UHV, but the $\mathrm{C}-\mathrm{H}$ bond cleavage, as found experimentally. Moreover, from the different paths proposed for the oxidation of methanol, ${ }^{17,18}$ the activation of the $\mathrm{O}-\mathrm{H}$ bond of methanol favors the path in which the scission of this bond to form adsorbed $\mathrm{CH}_{3} \mathrm{O}$ is followed by sequential dehydrogenation to adsorbed $\mathrm{CO} .{ }^{17,18}$

In summary, it has been here confidently established that methanol electro-oxidation on platinum in water takes place only in the presence of adsorbed $\mathrm{OH}$. Although the results were obtained for very low methanol concentrations, the onset potentials do not depend on the concentration, and the only change observed when increasing concentration is higher currents. $^{22}$ Weak surface interaction and significant barriers hinder the direct methanol activation on platinum at low overpotentials in the absence of adsorbed $\mathrm{OH}$. Before these direct dehydrogenation barriers begin to be surmountable favored as an effect of the potential, the surface is partially covered by adsorbed $\mathrm{OH}$ from the media. In the presence of adsorbed $\mathrm{OH}$, high adsorbed $\mathrm{OH}$ mobility on the surface, favorable methanol and adsorbed $\mathrm{OH}$ coadsorption, and favorable and virtually barrier-less hydrogen transference from the hydroxy group of methanol to adsorbed $\mathrm{OH}$ result in the immediate activation of methanol. As soon as the molecule approaches the surface, the favorable reaction of adsorbed $\mathrm{OH}$ yields adsorbed methoxy. These mechanisms would operate on the three basal planes of platinum. The present work stands in for a paradigm shift in the understanding of how alcohols are electrochemically oxidized in model systems, demonstrating the key role that species from the media play in the reaction mechanisms and evidencing that engineering different adsorption scenarios can profoundly impact the electrocatalysis of these processes.

\section{ASSOCIATED CONTENT}

\section{(s) Supporting Information}

The Supporting Information is available free of charge at https://pubs.acs.org/doi/10.1021/acscatal.1c05122.

Experimental and computational methods, additional voltammograms for methanol oxidation on different single crystal electrodes, and methanol dehydrogenation energy profiles (PDF)

\section{AUTHOR INFORMATION}

\section{Corresponding Authors}

Adolfo Ferre-Vilaplana - Instituto Tecnológico de Informática, Ciudad Politécnica de la Innovación, E-46022 Valencia, Spain; Departamento de Sistemas Informáticos y Computación, Escuela Politécnica Superior de Alcoy, Universidad Politécnica de Valencia, E-03801 Alcoy, Spain; ๑1 orcid.org/0000-0002-9032-9015; Email: aferre@ dsic.upv.es

Enrique Herrero - Instituto de Electroquímica, Universidad de Alicante, E-03080 Alicante, Spain; 이이.org/00000002-4509-9716; Email: herrero@ua.es

\section{Authors}

Dalila S. Mekazni - Instituto de Electroquímica, Universidad de Alicante, E-03080 Alicante, Spain

Rosa M. Arán-Ais - Instituto de Electroquímica, Universidad de Alicante, E-03080 Alicante, Spain

Complete contact information is available at:

https://pubs.acs.org/10.1021/acscatal.1c05122

\section{Notes}

The authors declare no competing financial interest.

\section{ACKNOWLEDGMENTS}

This research was funded by Ministerio de Ciencia e Innovación (Spain) Grant No. PID2019-105653GB-I00) and Generalitat Valenciana (Spain) Grant No. PROMETEO/ 2020/063. R.M.A.-A. acknowledges financial support from Generalitat Valenciana (Grant No. CDEIGENT/2019/018).

\section{REFERENCES}

(1) Fukuzumi, S. Production of Liquid Solar Fuels and Their Use in Fuel Cells. Joule 2017, 1 (4), 689-738.

(2) Zhao, X.; Yin, M.; Ma, L.; Liang, L.; Liu, C.; Liao, J.; Lu, T.; Xing, W. Recent Advances in Catalysts for Direct Methanol Fuel Cells. Energy Environ. Sci. 2011, 4 (8), 2736-2753.

(3) Huang, M.; Dong, G.; Wang, N.; Xu, J.; Guan, L. Highly Dispersive Pt Atoms on the Surface of RuNi Nanoparticles with Remarkably Enhanced Catalytic Performance for Ethanol Oxidation. Energy Environ. Sci. 2011, 4 (11), 4513-4516. 
(4) Hong, W.; Shang, C.; Wang, J.; Wang, E. Bimetallic PdPt Nanowire Networks with Enhanced Electrocatalytic Activity for Ethylene Glycol and Glycerol Oxidation. Energy Environ. Sci. 2015, 8 (10), 2910-2915.

(5) Parsons, R.; Vandernoot, T. The Oxidation of Small Organic Molecules: A Survey of Recent Fuel Cell Related Research. J. Electroanal. Chem. 1988, 257 (1-2), 9-45.

(6) Koper, M. T. M. T. M.; Lai, S. C. C. S.; Herrero, E. Mechanisms of the Oxidation of Carbon Monoxide and Small Organic Molecules at Metal Electrodes. In Fuel Cell Catalysis: A Surface Science Approach; Koper, M. T. M., Ed.; John Wiley \& Sons: Hoboken, NJ, USA, 2009; pp 166-171. DOI: 10.1002/9780470463772.ch6.

(7) Sriramulu, S.; Javi, T. D.; Stuve, E. M. Kinetic Modeling of Electrocatalytic Reactions: Methanol Oxidation on Platinum Electrodes. In Interfacial Electrochemistry, Theory, Experiments and Applications; Wieckowski, A., Ed.; Marcel Dekker: New York, 1998; p 793.

(8) Markovic, N. M.; Ross, P. N. Surface Science Studies of Model Fuel Cell Electrocatalysts. Surf. Sci. Rep. 2002, 45 (4-6), 117-229.

(9) Zhu, Y.; Bu, L.; Shao, Q.; Huang, X. Subnanometer PtRh Nanowire with Alleviated Poisoning Effect and Enhanced C-C Bond Cleavage for Ethanol Oxidation Electrocatalysis. ACS Catal. 2019, 9 (8), 6607-6612.

(10) Kakati, N.; Maiti, J.; Lee, S. H.; Jee, S. H.; Viswanathan, B.; Yoon, Y. S. Anode Catalysts for Direct Methanol Fuel Cells in Acidic Media: Do We Have Any Alternative for Pt or Pt-Ru? Chem. Rev. 2014, 114 (24), 12397-12429.

(11) Sheng, T.; Tian, N.; Zhou, Z.-Y.; Lin, W.-F.; Sun, S.-G. Designing Pt-Based Electrocatalysts with High Surface Energy. ACS Energy Lett. 2017, 2 (8), 1892-1900.

(12) Rizo, R.; Roldan Cuenya, B. Shape-Controlled Nanoparticles as Anodic Catalysts in Low-Temperature Fuel Cells. ACS Energy Lett. 2019, 4 (6), 1484-1495.

(13) Shi, Q.; He, Y.; Bai, X.; Wang, M.; Cullen, D. A.; Lucero, M.; Zhao, X.; More, K. L.; Zhou, H.; Feng, Z.; Liu, Y.; Wu, G.; et al. Methanol Tolerance of Atomically Dispersed Single Metal Site Catalysts: Mechanistic Understanding and High-Performance Direct Methanol Fuel Cells. Energy Environ. Sci. 2020, 13 (10), 3544-3555.

(14) Mao, J.; Chen, W.; He, D.; Wan, J.; Pei, J.; Dong, J.; Wang, Y.; An, P.; Jin, Z.; Xing, W. Design of Ultrathin Pt-Mo-Ni Nanowire Catalysts for Ethanol Electrooxidation. Sci. Adv. 2017, 3 (8), e1603068.

(15) Zhang, Z.; Liu, J.; Wang, J.; Wang, Q.; Wang, Y.; Wang, K.; Wang, Z.; Gu, M.; Tang, Z.; Lim, J.; et al. Single-Atom Catalyst for High-Performance Methanol Oxidation. Nat. Commun. 2021, 12 (1), $1-9$.

(16) Rizo, R.; Arán-Ais, R. M.; Herrero, E. On the Oxidation Mechanism of C1-C2 Organic Molecules on Platinum. A Comparative Analysis. Curr. Opin. Electrochem. 2021, 25, 100648.

(17) Greeley, J.; Mavrikakis, M. A First-Principles Study of Methanol Decomposition on Pt(111). J. Am. Chem. Soc. 2002, 124 (24), 71937201.

(18) Greeley, J.; Mavrikakis, M. Competitive Paths for Methanol Decomposition on $\mathrm{Pt}(111)$. J. Am. Chem. Soc. 2004, 126 (12), 39103919.

(19) Corrigan, D. S.; Weaver, M. J. Mechanisms of Formic Acid, Methanol, and Carbon Monoxide Electrooxidation at Platinum as Examined by Single Potential Alteration Infrared Spectroscopy. J. Electroanal. Chem. Interfacial Electrochem. 1988, 241 (1-2), 143-162.

(20) Franaszczuk, K.; Herrero, E.; Zelenay, P.; Wieckowski, A.; Wang, J.; Masel, R. I. I. A Comparison of Electrochemical and GasPhase Decomposition of Methanol on Platinum Surfaces. J. Phys. Chem. 1992, 96 (21), 8509-8516.

(21) Herrero, E.; Franaszczuk, K.; Wieckowski, A. Electrochemistry of Methanol at Low Index Crystal Planes of Platinum: An Integrated Voltommetric and Chronoamperometric Study. J. Phys. Chem. 1994, 98 (19), 5074-5083.

(22) Kamyabi, M. A.; Martínez-Hincapié, R.; Feliu, J. M.; Herrero, E. Effects of the Interfacial Structure on the Methanol Oxidation on Platinum Single Crystal Electrodes. Surfaces 2019, 2 (1), 177-192.
(23) Cao, D.; Lu, G. Q.; Wieckowski, A.; Wasileski, S. A.; Neurock, M. Mechanisms of Methanol Decomposition on Platinum: A Combined Experimental and Ab Initio Approach. J. Phys. Chem. B 2005, 109 (23), 11622-11633.

(24) Neurock, M.; Janik, M.; Wieckowski, A. A First Principles Comparison of the Mechanism and Site Requirements for the Electrocatalytic Oxidation of Methanol and Formic Acid over Pt. Faraday Discuss. 2009, 140 (0), 363-378.

(25) Hartnig, C.; Grimminger, J.; Spohr, E. The Role of Water in the Initial Steps of Methanol Oxidation on $\mathrm{Pt}(2[$ Thin Space]1[Thin Space]1). Electrochim. Acta 2007, 52 (6), 2236-2243.

(26) Kizhakevariam, N.; Stuve, E. M. Promotion and Poisoning of the Reaction of Methanol on Clean and Modified Platinum (100). Surf. Sci. 1993, 286 (3), 246-260.

(27) Rodriguez, P.; Koverga, A. A.; Koper, M. T. M. Carbon Monoxide as a Promoter for Its Own Oxidation on a Gold Electrode. Angew. Chemie-International Ed. 2010, 49 (7), 1241-1243.

(28) Auer, A.; Andersen, M.; Wernig, E. M.; Hörmann, N. G.; Buller, N.; Reuter, K.; Kunze-Liebhäuser, J. Self-Activation of Copper Electrodes during $\mathrm{CO}$ Electro-Oxidation in Alkaline Electrolyte. Nat. Catal. 2020, 3 (10), 797-803.

(29) Grozovski, V.; Vidal-Iglesias, F. J.; Herrero, E.; Feliu, J. M. Adsorption of Formate and Its Role as Intermediate in Formic Acid Oxidation on Platinum Electrodes. ChemPhysChem 2011, 12 (9), $1641-1644$.

(30) Gómez, R.; Orts, J. M.; Alvarez-Ruiz, B.; Feliu, J. M. Effect of Temperature on Hydrogen Adsorption on $\mathrm{Pt}(111), \operatorname{Pt}(110)$, and $\mathrm{Pt}(100)$ Electrodes in 0.1 M HClO4. J. Phys. Chem. B 2004, 108 (1), 228-238.

(31) Lasia, A. Modeling of Hydrogen Upd Isotherms. J. Electroanal. Chem. 2004, 562 (1), 23-31.

(32) Domke, K.; Herrero, E.; Rodes, A.; Feliu, J. M. Determination of the Potentials of Zero Total Charge of $\mathrm{Pt}(100)$ Stepped Surfaces in the [011] Zone. Effect of the Step Density and Anion Adsorption. J. Electroanal. Chem. 2003, 552 (SUPPL), 115-128.

(33) Lamy, C.; Leger, J. M.; Clavilier, J.; Parsons, R. Structural Effects in Electrocatalysis: A Comparative Study of the Oxidation of $\mathrm{CO}, \mathrm{HCOOH}$ and $\mathrm{CH} 3 \mathrm{OH}$ on Single Crystal Pt Electrodes. J. Electroanal. Chem. 1983, 150 (1-2), 71-77.

(34) Grozovski, V.; Climent, V.; Herrero, E.; Feliu, J. M. The Role of the Surface Structure in the Oxidation Mechanism of Methanol. J. Electroanal. Chem. 2011, 662 (1), 43-51.

(35) Housmans, T. H. M.; Wonders, A. H.; Koper, M. T. M. Structure Sensitivity of Methanol Electrooxidation Pathways on Platinum: An On-Line Electrochemical Mass Spectrometry Study. J. Phys. Chem. B 2006, 110 (20), 10021-10031.

(36) Herrero, E.; Álvarez, B.; Feliu, J. M.; Blais, S.; RadovicHrapovic, Z.; Jerkiewicz, G. Temperature Dependence of the COadsoxidation Process on $\operatorname{Pt}\left(\begin{array}{lll}1 & 1 & 1\end{array}\right), \operatorname{Pt}\left(\begin{array}{lll}1 & 0 & 0\end{array}\right)$, and $\operatorname{Pt}\left(\begin{array}{lll}1 & 1 & 0\end{array}\right)$ Electrodes. J. Electroanal. Chem. 2004, 567 (1), 139-149.

(37) Garcia-Araez, N.; Climent, V.; Feliu, J. M. Analysis of Temperature Effects on Hydrogen and $\mathrm{OH}$ Adsorption on $\mathrm{Pt}\left(\begin{array}{ll}1 & 1\end{array}\right.$ 1), $\operatorname{Pt}\left(\begin{array}{lll}1 & 0 & 0\end{array}\right)$ and $\operatorname{Pt}\left(\begin{array}{lll}1 & 1 & 0\end{array}\right)$ by Means of Gibbs Thermodynamics. J. Electroanal. Chem. 2010, 649 (1-2), 69-82. 